\title{
$\checkmark$ EDITOR'S CHOICE \\ A randomised tandem colonoscopy trial of narrow band imaging versus white light examination to compare neoplasia miss rates
}

\author{
T Kaltenbach, S Friedland, R Soetikno
}

VA Palo Alto HCS, Stanford University School of Medicine, Palo Alto, CA, USA

Correspondence to: Dr R Soetikno, VA Palo Alto Health Care System, Stanford University School of Medicine, 3801 Miranda Ave, GI-111, Palo Alto, CA 94304, USA: soetikno@earthlink.net

Revised 5 May 2008 Accepted 14 May 2008 Published Online First 3 June 2008

\begin{abstract}
Objective: Colonoscopy, the "gold standard" screening test for colorectal cancer (CRC), has known diagnostic limitations. Advances in endoscope technology have focused on improving mucosal visualisation. In addition to increased angle of view and resolution features, recent colonoscopes have non-white-light optics, such as narrow band imaging (NBI), to enhance image contrast. We aimed to study the neoplasia diagnostic characteristics of NBI, by comparing the neoplasm miss rate when the colonoscopy was performed under $\mathrm{NBI}$ versus white light (WL).

Design: Randomised controlled trial.

Setting: US Veterans hospital.

Patients: Elective colonoscopy adults.

Intervention: We randomly assigned patients to undergo a colonoscopic examination using NBI or WL. All patients underwent a second examination using WL, as the reference standard.
\end{abstract}

Main outcome measures: The primary end point was the difference in the neoplasm miss rate, and secondary outcome was the neoplasm detection rate.

Results: In 276 tandem colonoscopy patients, there was no significant difference of miss or detection rates between NBI or WL colonoscopy techniques. Of the 135 patients in the NBI group, 17 patients (12.6\%; 95\% confidence interval (CI) 7.5 to $19.4 \%$ ) had a missed neoplasm, as compared with 17 of the 141 patients (12.1\%; $95 \% \mathrm{Cl} 7.2$ to $18.6 \%$ ) in the WL group, with a miss rate risk difference of $0.5 \%(95 \% \mathrm{Cl}-7.2$ to 8.3$)$. 130 patients (47\%) had at least one neoplasm. Missed lesions with $\mathrm{NBI}$ showed similar characteristics to those missed with WL. All missed neoplasms were tubular adenomas, the majority (78\%) was $\leqslant 5 \mathrm{~mm}$ and none were larger than $1 \mathrm{~cm}$ (one-sided $95 \% \mathrm{Cl}$ up to $1 \%$ ). Nonpolypoid lesions represented 35\% (13/37) of missed neoplasms.

Interpretation: NBI did not improve the colorectal neoplasm miss rate compared to $\mathrm{WL}$; the miss rate for advanced adenomas was less than $1 \%$ and for all adenomas was $12 \%$. The neoplasm detection rates were similar high using NBI or WL; almost a half the study patients had at least one adenoma.

Clinicaltrials.gov identifier: NCT00628147

Advances in colonoscopy technology hold the potential to improve the prevention efforts for colorectal cancer (CRC). Optimising the detection of precursors of advanced CRC is important as it is the third most commonly diagnosed cancer in the US and UK. Colon cancer is preventable, with up to $90 \%$ of CRC related deaths potentially prevented with colonoscopy. ${ }^{12}$ Although, colonoscopy is currently the "gold standard" screening modality for CRC, ${ }^{34}$ it has diagnostic limitations. Studies of tandem colonoscopy have shown an overall neoplasm miss rate of $22 \%^{5}$ and that a substantial percentage $(30 \%)$ of patients have a missed neoplasm. ${ }^{6}$ The miss rates are of concern, considering the potential progression to CRC. Reports of cancers diagnosed within a short period following a putatively clearing colonoscopy are as high as 2.4 cancers/1000 person-years. ${ }^{7}$ A number of factors may contribute to the reduced effectiveness of screening colonoscopy. These include the lesion characteristics, such as being located behind folds, at flexures, or in the rectum, ${ }^{89}$ or having a less conspicuous non-polypoid shape. ${ }^{10}{ }^{11}$ In addition, the quality of bowel preparation, ${ }^{12}$ and the operator insertion and withdrawal technique $e^{13-15}$ may not be adequate.

Recent technology has led to the development of colonoscopes that are specifically designed to further improve visualisation, including wide angle of view $\left(170^{\circ}\right.$ vs $\left.140^{\circ}\right)$ and high resolution or high definition. These colonoscopes are also equipped with instantaneous non-white light imaging capabilities that are designed to enhance image contrast and potentially improve the visualisation of lesions. The narrow band imaging (NBI) feature operates with the switch of a button at the control body of the endoscope. The NBI technology uses a narrowed light source centred at $415 \mathrm{~nm}$ (blue) and $540 \mathrm{~nm}$ (green). The narrowed light penetrates primarily the mucosa and submucosa and is absorbed primarily by haemoglobin. Thus, surface microvessels are visible as dark structures. ${ }^{16}$ Because the density and shape of microvessels change in neoplasia, NBI may potentially aid the endoscopist in the diagnosis of neoplasm. ${ }^{17}$ As such, we hypothesised that the use of NBI would improve the identification of neoplasms through the colour differentiation of neoplastic lesion (appearing brown) from normal mucosa (appearing green) (fig 1), and potentially lead to a reduction in neoplasm miss rate. We aimed to study the neoplasm miss rate, and compare NBI to white light.

\section{METHODS}

\section{Study design}

We conducted a randomised controlled trial in a large Veterans Affairs hospital in California. All patients provided written informed consent for participation in the trial.

\section{Study population}

We recruited consecutive adult patients who were referred for elective outpatient colonoscopy in the 

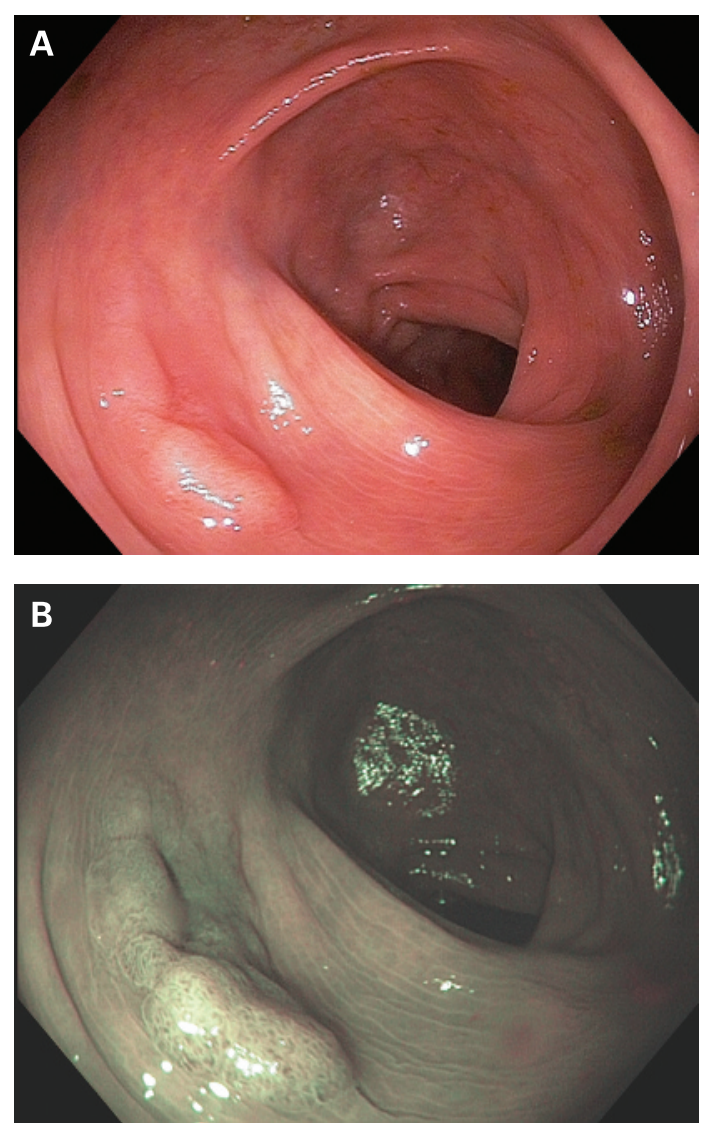

Figure 1 A superficially elevated neoplasm as seen using the white light $(A)$ and narrow band imaging $(B)$.

endoscopy unit of the VAPAHCS from January 2006 to February 2007. One of six participating endoscopists enrolled patients for inclusion in the trial. We excluded patients with known inflammatory bowel disease, personal or family history of polyposis syndrome, or referred for evaluation of a known lesion.

\section{Study procedure}

Preparation and sedation

Patients were permitted to eat low-residue foods on the day before colonoscopy. Routine bowel preparation included 4 litres of PEG-3350 (GoLYTELY; Braintree Laboratories, Braintree, Massachusetts, USA) and $296 \mathrm{ml}$ of magnesium citrate (Cumberland Swan, Smyrna, Tennessee, USA). Subjects received conscious sedation with intravenous midazolam and fentanyl.

\section{Device}

We used adult colonoscopes with wide angle of view $\left(170^{\circ}\right)$ and NBI capabilities. In the NBI group, we used the prototype of the CFH180AL, XCF-H160AY2L, and in the WL group, we used the prototype of the CF180AL, XCF-O160W6L (Olympus Medical Systems, Hachioji, Japan). Evis Exera II CV-160A video processors (prototype of the Evis Exera II CV-180; Olympus Medical Systems) and high definition $(1280 \times 1024)$ monitors (NDS Surgical Imaging, San Jose, California, USA) processed and displayed the video images in both arms, respectively.

\section{Preparation for the study}

Prior to initiation of the study, we developed the proficiency to diagnose polyps using NBI. We recorded uncompressed digital video of the cases (http://www.apple.com/science/profiles/ paloalto/ (accessed 21 July 2008)) and correlated endoscopic and pathological findings in 111 patients. At the same time, engineers from Olympus optimised the endoscope system and subsequently commercialised it as the Excera II 180 system. We used this system in the study.

\section{Procedure}

Six endoscopists, each with experience in more than 500 colonoscopies, participated in the study. Following patient enrolment, and immediately prior to the examination, we randomised patients to NBI or WL using a witnessed coin flip. We did not adjust the coin flip sequence during the randomisation process in order to maintain equal groups. In the NBI group, endoscopists completed the first examination with NBI and an immediate second examination using WL. In the control WL group, endoscopists performed both examinations using WL. During withdrawal, the endoscopist systematically inspected the mucosa for lesions. Each patient underwent back-to-back colonoscopy by the same endoscopist. It was not possible to blind the endoscopist to the imaging intervention, and, logistically, it was not possible to have a different endoscopist perform the second examination.

\section{End points}

The primary study end point was the neoplasm miss rate. We used a repeat colonoscopy as the reference standard. We removed any identified lesion at the time of initial detection, such that the endoscopist performed the second examination in a colon putatively cleared of lesions. Hence, we defined a "missed" lesion as one identified during insertion or withdrawal of the second examination. We calculated the neoplasm miss rates using both patient and neoplasm based analyses.

We determined the "per patient" neoplasm miss rate by the number of patients with detected neoplasm(s) during the second examination divided by the total number of patients examined, according to the type of imaging technique used for the first examination. The denominator included the total number of patients examined regardless of the number of lesions detected. We determined the "per neoplasm" neoplasm miss rate by the number of detected neoplasm(s) during the second examination divided by the number of neoplasm detected overall according to the type of imaging technique used for the first examination.

We recorded study findings using a computerised database program (FileMaker Pro; FileMaker, Santa Clara, California, USA). Secondary end points included neoplasm detection rates, completion of examinations, and complications. A detected lesion was defined as a lesion identified during the first examination. Additional study measurements included withdrawal time, patient and lesion characteristics, and quality of bowel preparation. We defined withdrawal time as the time from initiation of caecal inspection to the time when the colonoscope was withdrawn from the anus. Using a stopwatch, an endoscopy nurse recorded withdrawal times. The stopwatch was paused during prolonged mucosal washing or suctioning of luminal fluid, as well as during therapeutic manoeuvres. Withdrawal times were targeted to be at least $6 \mathrm{~min}$ in each examination to allow for adequate inspection. ${ }^{18} 19$ Though it was notably more efficient to withdrawal during the second examination (given that mucosa had been just cleaned and lumen insufflated from the first pass), we did not attempt to purposefully adjust withdrawal times between the two examinations to keep them equal. 


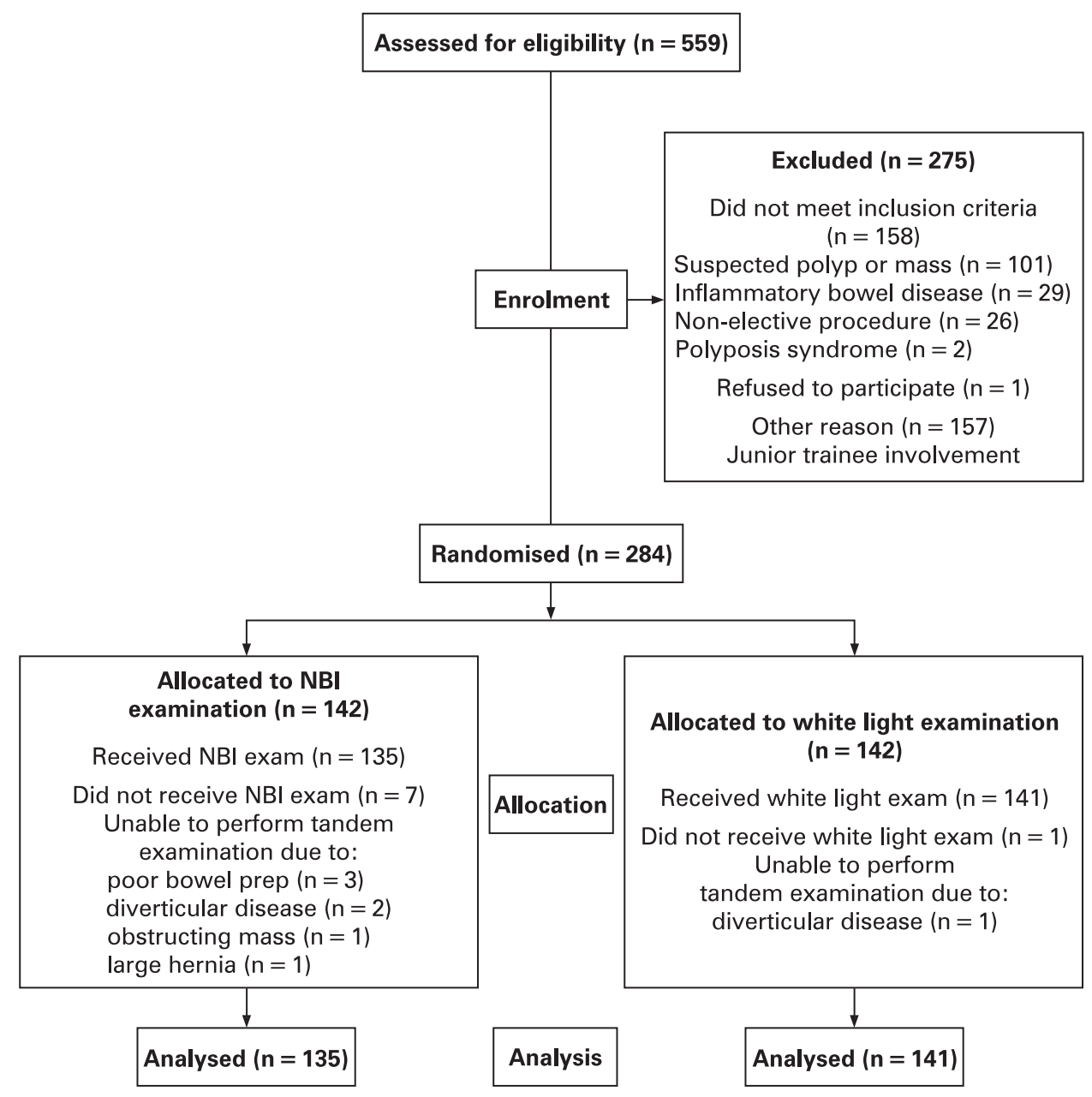

Figure 2 Flow diagram.

We used standard morphology classification described by the Japanese Research Society for Cancer of the Colon and Rectum, ${ }^{20}$ which has been a routine practice in our unit since 1999. ${ }^{11}$ We assessed the lesion size using the span of an opened biopsy forceps. We performed standard biopsy, polypectomy or endoscopic mucosal resection as needed, and submitted specimens separately for pathological evaluation. We used histopathology classifications according to the World Health Organization system. ${ }^{21}$ Using a validated score, we categorised the quality of bowel preparation into excellent, good, fair, poor or inadequate. ${ }^{22}$

\section{Statistical analysis}

\section{Sample size calculation}

We calculated an enrolment of 120 patients in each group for the study to have a statistical power of $80 \%$ to detect an absolute reduction of $15 \%$ (from $30 \%$ ) in the neoplasm miss rate with the use of NBI colonoscope, with a two-sided level of 0.05 . Assuming a $90 \%$ successful caecal intubation rate, and that $8 \%$ of our patients may have a poor quality bowel preparation, we then calculated that we would need to enrol a total of 142 patients in each group.

\section{Analysis}

We performed statistical analyses using Stata/SE 9.2 for Macintosch (Stata Corporation, College Station, Texas, USA). For univariate analysis, we used the test or Wilcoxon rank sum test to compare normally distributed or non-parametric continuous predictors, respectively. We performed univariate analysis of categorical variables using the $\chi^{2}$ test. The Pearson correlation coefficient ( $r$ ) measured the linear relationship between withdrawal time and neoplasms missed and detected. The odds ratios with $95 \%$ confidence interval served to describe the influence of imaging modality on miss rates. We considered differences to be significant if the two-tailed $p$ value was $<0.05$.

We performed the multivariate analyses of the association of missed neoplasms with the imaging modality using a simple logistic regression. We explored the influence of lesion size, morphology and quality of bowel preparation on the model, and also assessed the individual endoscopist as a potential confounder. In addition, we performed tests of interaction between withdrawal time and the primary outcome.

\section{RESULTS}

\section{Patients}

During a 13-month period between January 2006 and February 2007, we enrolled a total of 284 patients; 142 into the intervention (NBI) colonoscopy and 142 into the control (WL) colonoscopy groups (fig 2). After allocation, we excluded patients with an incomplete first or second colonoscopy (defined by the inability to intubate the colonoscope to the caecum, or patients with a poor quality bowel preparation. In total, we excluded eight patients (seven in the NBI group: poor quality bowel preparation $(n=3)$, severe diverticular disease 
Table 1 Baseline patient characteristics, $n=284 *$

\begin{tabular}{|c|c|c|c|}
\hline & $\begin{array}{l}\text { Narrow band } \\
\text { imaging, } n=142\end{array}$ & $\begin{array}{l}\text { White light } \\
\text { imaging, } n=142\end{array}$ & p Value \\
\hline Mean age, years (SD) & $64(10)$ & $64(10)$ & 0.93 \\
\hline Male, n (\%) & $137(96)$ & 138 (97) & 0.5 \\
\hline \multicolumn{4}{|l|}{ Race, n (\%) } \\
\hline White & $98(69)$ & $109(77)$ & 0.14 \\
\hline Hispanic & $13(9)$ & $13(9)$ & 1.0 \\
\hline African-American/Black & $13(9)$ & $10(7)$ & 0.51 \\
\hline Asian/Pacific Islander & $18(13)$ & $10(7)$ & 0.11 \\
\hline \multicolumn{4}{|l|}{ Indication, n (\%) } \\
\hline Screening & $69(49)$ & $75(53)$ & 0.48 \\
\hline History of polyps & $46(32)$ & $43(30)$ & 0.70 \\
\hline Anaemia & $9(6)$ & $6(4)$ & 0.43 \\
\hline $\begin{array}{l}\text { Positive faecal occult } \\
\text { blood test }\end{array}$ & $5(4)$ & $4(3)$ & 0.73 \\
\hline Change in stool pattern & $4(3)$ & $4(3)$ & 1.0 \\
\hline Rectal bleeding & $4(3)$ & $4(3)$ & 1.0 \\
\hline Weight loss & $2(1)$ & $2(1)$ & 1.0 \\
\hline $\begin{array}{l}\text { Personal history of colon } \\
\text { cancer }\end{array}$ & $2(1)$ & $0(0)$ & 0.5 \\
\hline Abdominal pain & $1(1)$ & $4(3)$ & 0.37 \\
\hline \multicolumn{4}{|l|}{ Sedation $\dagger$} \\
\hline Fentanyl, $\mu \mathrm{g}$ (SD) & $100(50)$ & $100(50)$ & 0.26 \\
\hline Midazolam, mg (SD) & $2(1)$ & $2(1)$ & 0.66 \\
\hline \multicolumn{4}{|l|}{$\begin{array}{l}\text { Quality of bowel } \\
\text { preparation†, } n(\%)\end{array}$} \\
\hline Excellent & $57(42)$ & $62(44)$ & 0.81 \\
\hline Good & $59(44)$ & $61(43)$ & 1.0 \\
\hline Fair & $19(14)$ & $18(13)$ & 0.86 \\
\hline \multicolumn{4}{|l|}{ Withdrawal time†, $\min (\mathrm{SD})$} \\
\hline Examination 1 & $8.9(2.6)$ & $7.6(2.3)$ & $<0.001$ \\
\hline Examination 2 & $6.3(2)$ & $6.2(1.8)$ & 0.54 \\
\hline
\end{tabular}

*Following randomisation, eight patients (narrow band imaging, $n=7$; white light imaging, $\mathrm{n}=1$ ) were excluded from the study due to inability to undergo tandem colonoscopy or poor bowel preparation quality. All excluded patients were male and white. Procedure indications of the excluded patients were screening $(n=2)$ and history of polyps $(n=5)$ in the narrow band imaging group and abdominal pain $(n=1)$ in the white light imaging group.

†Based on 276 patients who successfully underwent tandem colonoscopy: narrow band imaging (135) and white light imaging (141).

$(\mathrm{n}=2)$, large inguinal hernia $(\mathrm{n}=1)$ and obstructing mass $(\mathrm{n}=1)$ ) and one in the WL group due to severe diverticular disease. The caecum was intubated in 97 and $100 \%$ of cases for the first examination; and in 95 and $99 \%$ of cases for the second examination, in the NBI and WL groups, respectively. We did not observe any complications.

Baseline demographic characteristics were similar between groups (table 1). The majority of patients were men (97\%); with a mean age of 64 (SD 10) years (range 31 to 89). Screening (51\%) and polyp surveillance (31\%) were the predominant indications for the procedure. The mean sedation doses of fentanyl (100 (SD 50) $\mu \mathrm{g}$ ) and midazolam (2 (SD 1) mg), as well as the quality of the bowel preparation, were similar across groups.
Though both groups had a 6 min second examination withdrawal time to evaluate for "missed" lesions, the mean withdrawal time of the first examination was 1 min longer in the NBI (9 (SD 2.5) min) compared to WL (8 (SD 2) $\mathrm{min}$ ); $\mathrm{p}<0.001$.

\section{Neoplasm miss rates}

Neoplasm miss rate per patient

We found a total of 37 missed neoplasms in 34 patients, and there appeared to be no significant difference in the rate of missed lesions between the NBI and WL groups (table 2). Of the 135 patients in the NBI group, 17 patients $(12.6 \%$; 95\% CI 7.5 to $19.4 \%)$ had a neoplasm missed during the first colonoscopic examination, as compared with 17 of the 141 patients $(12.1 \%$; $95 \%$ CI 7.2 to $18.6 \%$ ) in the WL group, with a miss rate risk difference of $0.5 \%$ ( $95 \%$ CI -7.2 to 8.3 ). The odds ratio for a missed neoplasm using NBI is 0.94 with a CI from 0.47 to 1.85 , further suggesting no association between colonoscopy using $\mathrm{NBI}$ and a decrease in the neoplasm miss rate compared to colonoscopy using WL.

We found a $12.3 \%$ (95\% CI 8.7 to $16.8 \%$ ) per patient miss rate for neoplasm of any size and $2.5 \%$ (95\% CI 1.0 to $5.2 \%$ ) for neoplasms $\geqslant 6 \mathrm{~mm}$. No lesion larger than $1 \mathrm{~cm}$ was missed (one-sided $95 \%$ CI 0 to $1.1 \%$ ). Most patients (85\%) with an adenoma found on the second colonoscopy had at least one neoplasm detected on the first examination. However, $1.8 \%$ of the patients $(\mathrm{n}=5 ; \mathrm{NBI}=2, \mathrm{WL}=3$ ), had an adenoma (mean size $3.6(\mathrm{SD} 1.1) \mathrm{mm}$ ) detected only on the second examination.

\section{Neoplasm miss rates per lesion}

The number of lesions identified during the first and second examinations, according to the imaging modality, are shown in table 3. Of the 164 neoplastic lesions detected in the NBI group, 20 neoplasms (12.2\%; $95 \%$ CI 7.6 to $18.2 \%$ ) were missed during the first colonoscopic examination, as compared with 17 of the 132 neoplasms (12.9\%; 95\% CI 7.7 to $19.8 \%$ ) in the WL group. The overall per neoplasm miss rate was $12.5 \%$ (95\% CI 9.0 to $16.8 \%)$.

The characteristics of the missed lesions did not significantly differ between groups (table 4). Non-polypoid (flat) lesions represented 35\% (13/37) of missed neoplasms. The median (and mean) size of a missed neoplasm was $4 \mathrm{~mm}$. All missed neoplasms were tubular adenomas. One missed adenoma measured $1 \mathrm{~cm}$. No lesion larger than $1 \mathrm{~cm}$, villous histological features, high-grade dysplasia, or invasive cancer was missed.

\section{Neoplasm detection rates}

In total, we report a $47 \%$ adenoma detection rate, reflecting the detection of 259 neoplasms in 130 patients during the first colonoscopic examination. We found no significant difference in the percentage of patients with neoplasm between the NBI $(50 \%)$ and WL $(44 \%) ; p=0.29$. During the second colonoscopic examination, we identified an additional 37 neoplasms in 34

Table 2 Patient neoplasm miss rate: percentage of subjects with neoplastic lesion on second examination

\begin{tabular}{clll}
\hline & \multicolumn{2}{l}{ Patient neoplasm miss rate, \% $(\mathbf{9 5 \%} \mathbf{~ C l})$} & \multicolumn{2}{l}{$\begin{array}{l}\text { Miss rate risk difference, \% } \\
\text { (95\% Cl) }\end{array}$} \\
\cline { 2 - 3 } & Narrow band imaging, $\mathbf{n}=\mathbf{1 3 5}$ & White light imaging, $\mathbf{n = 1 4 1}$ & $0.5 \%(-7.2$ to 8.3$)$ \\
Any adenoma & $12.6 \%(7.5$ to 19.4$)$ & $12.1 \%(7.2$ to 18.6$)$ & $1.2 \%(-5.9$ to 8.2$)$ \\
$\leqslant 5 \mathrm{~mm}$ & $10.4 \%(5.8$ to 16.8$)$ & $9.2 \%(5.0$ to 15.3$)$ & $-0.6 \%(-4.3$ to 3.1$)$ \\
$6-9 \mathrm{~mm}$ & $2.2 \%(0.5$ to 6.4$)$ & $2.8 \%(0.8$ to 7.1$)$ & $0.7 \%(-0.7$ to 2.2$)$ \\
$\geqslant 10 \mathrm{~mm}$ & $0.7 \%{ }^{*}(0.02$ to 4.1$)$ & $0 \%(0$ to 2.1$)$ & \\
\hline
\end{tabular}

*"Missed" lesion was a $10 \mathrm{~mm}$ tubular adenoma.

$\mathrm{Cl}$, confidence interval. 
Table 3 Number of colorectal lesions at the first and second colonoscopic examinations

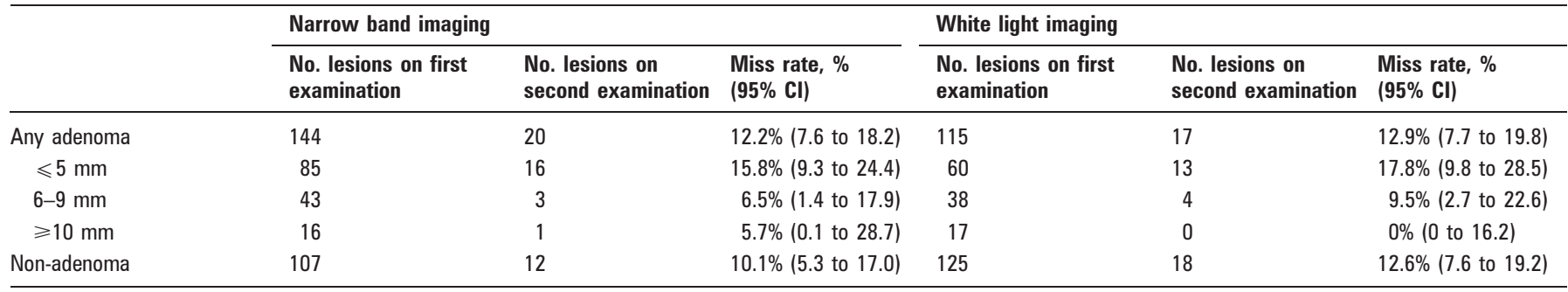

$\mathrm{Cl}$, confidence interval.

patients, five of whom had no neoplasm diagnosed during the first examination. Thus, we report an overall adenoma detection rate of $49 \%$ (135/276). We observed similar detection rates $(\mathrm{p}=0.12)$ in the screening $(45 \%(60 / 133) ; \mathrm{NBI} 44 \%(29 / 66)$ and WL 46\% (31/67)) and non-screening population (52\% (75/ 143); NBI 58\% (40/69) and WL 47\% (35/74)). We detected advanced neoplasms, defined as adenomas with a diameter of at least $10 \mathrm{~mm}$ or with villous histological features, high-grade dysplasia, or invasive cancer, in $9.4 \%$ of the study patients. We identified non-polypoid neoplasms in both groups, NBI $(n=40)$ and WL $(\mathrm{n}=22), \mathrm{p}=0.11$.

The mean number of neoplasms detected per patient on first colonoscopy was 0.98 (SD 1.49), range 0-12. High mean neoplasm detection rates were seen in both groups (NBI 1.1 (SD 1.75), range $0-12$ vs WL 0.87 (SD 1.17), range 0-5). Endoscopist-specific mean neoplasm detection rates on first colonoscopy varied insignificantly from 0.75 to 1.01 .

\section{Multivariate analysis}

Using a multivariate model, there was no significant influence of lesion size, morphology and quality of bowel preparation on the association of NBI with neoplasm miss and detection rates. Despite similar mean withdrawal time $(6 \mathrm{~min})$ during the

Table 4 Characteristics of "missed" colorectal neoplasms, $n=37$

\begin{tabular}{|c|c|c|c|}
\hline & $\begin{array}{l}\text { Narrow band } \\
\text { imaging, } n=20\end{array}$ & $\begin{array}{l}\text { White light } \\
\text { imaging, } n=17\end{array}$ & p Value \\
\hline Mean size, mm (SD) & $\begin{array}{l}4(2) \\
\text { (range, 2-10) }\end{array}$ & $\begin{array}{l}4(2) \\
\text { (range, 2-9) }\end{array}$ & 0.50 \\
\hline \multicolumn{4}{|l|}{ Shape $^{*}, \mathrm{n}(\%)$} \\
\hline Mass & $0(0)$ & $0(0)$ & - \\
\hline Polypoid † & $13(65)$ & $11(65)$ & 1.0 \\
\hline Non-polypoid: & $7(35)$ & $6(35)$ & 1.0 \\
\hline \multicolumn{4}{|l|}{ Location, n (\%) } \\
\hline Caecum & $1(5)$ & $2(12)$ & 0.58 \\
\hline Ascending colon & $5(25)$ & $2(12)$ & 0.42 \\
\hline Transverse colon & $6(30)$ & $8(47)$ & 0.33 \\
\hline Descending colon & $6(30)$ & $2(12)$ & 0.26 \\
\hline Sigmoid colon & $2(10)$ & $2(12)$ & 1.0 \\
\hline Rectum & $0(0)$ & $1(5)$ & 0.46 \\
\hline \multicolumn{4}{|c|}{ Withdrawal time, min (SD) } \\
\hline Examination 1 & $9.7(2.7)$ & $7.2(2)$ & 0.0017 \\
\hline Examination 2 & $6(1.4$ & $6.7(1.8)$ & 0.90 \\
\hline \multicolumn{4}{|c|}{ Quality of bowel preparation, $\mathrm{n}(\%)$} \\
\hline Excellent & $5(25)$ & $6(35)$ & 0.72 \\
\hline Good & $10(50)$ & $9(53)$ & 1.0 \\
\hline Fair & $5(25)$ & $2(12)$ & 0.42 \\
\hline
\end{tabular}

${ }^{*}$ Described by the Japanese Society for Cancer of the Colon and Rectum. ${ }^{20}$ tThe polypoid type comprise of pedunculated (Ip), semipedunculated (Ips) and sessile (Is). \$The non-polypoid type includes superficially elevated (Ila), completely flat (Ilb), and depressed (IIc). lesions. The superficially elevated lesions are colloquially referred to as flat lesions due to extremely rare prevalence of the completely flat (Illb) lesions. second colonoscopy in both groups, missed neoplasms in the NBI arm were associated with longer first colonoscopy withdrawal time (10 (SD 2.5) min) compared to missed neoplasms in the WL arm (7 (SD 2) min) $(p<0.002)$. Nonetheless, we failed to detect an interaction between withdrawal time and missed neoplasm. Further analysis by controlling for withdrawal time, according to slow withdrawal ( $>6 \mathrm{~min}$ ) and fast withdrawal $(<6 \mathrm{~min})$, did not significantly change the effect of neoplasm detection or miss rates, suggesting that withdrawal time was not on the causal pathway.

Using $\chi^{2}$, we determined that the estimated odds ratios $(95 \%$ CI) for the association between missed neoplasm and NBI colonoscopy among endoscopists did not vary significantly. The test of homogeneity of odds ratios across the strata of endoscopists was not significant at the 5\% level, visual inspection of the component odds ratios showed overlapping confidence intervals, and the adjusted measure of association differed slightly from the crude estimate. We did not adjust for endoscopist in the multivariate analysis.

\section{DISCUSSION}

In this study, we did not find NBI to significantly influence the likelihood of missing or detecting a colorectal neoplasm compared to WL. The $12 \%$ miss rate observed in our study, however, is approximately half of that reported in a recent systematic review of the published literature on adenoma miss rate determined by tandem colonoscopy. ${ }^{5}$ Furthermore, we found high adenoma detection rates across screening and nonscreening populations to support our low miss rates. Our finding is complementary to that recently reported in randomised trials by Rex and Helbig, ${ }^{23}$ and Inoue and colleagues. ${ }^{24}$ Rex and Helbig found that NBI did not result in improved detection of adenomas. Inoue and colleagues had similar results, after Bonferroni correction. The high adenoma detection rates using NBI or WL in our predominantly male, veteran population as well as in the mixed gender groups studied by Rex and Inoue corroborate the finding that the lack of improved detection is not due to insufficient neoplasia detection. Rather, we suspect that the high detection rate of neoplasms, using either NBI or WL, actually led to the difficulty to show the diagnostic benefit of NBI.

Adler and colleagues, on the contrary, found a low prevalence of adenoma (17\%) in the WL arm and thus, report a trend for higher adenoma detection rate using NBI compared to WL. ${ }^{25}$ In a secondary analysis of consecutive groups of 100 patients, the authors report a continuous rise in the adenoma detection rate from 8 to $26.5 \%$ in the WL arm. Despite the rate of the NBI arm being unchanged, they speculated on a potential learning effect from the NBI image enhancement to improve recognition of lesions using WL. In our study, we found approximately 1.7-5.7 times the lower and upper range, respectively, the adenoma detection rates reported by Adler, and did not observe a learning curve. This is likely due to our sufficient training with the NBI 
system and its colour characteristics in normal mucosa, stool and colonic pathology, prior to the study initiation.

The biases of our study design gave NBI the best chance to succeed. Nonetheless, colonoscopy using NBI with high definition performed by an unblinded experienced endoscopist still did not lead to significant reductions in the miss rate or improvements in the detection rate compared to high resolution WL imaging. Although the current study represents the largest to date, considering that the $12 \%$ miss rate found in the control WL group is less than half of the $30 \%$ that we estimated, even larger tandem colonoscopy studies are necessary to provide adequate power to detect a small effect of NBI.

Currently, the perfect reference standard for determining the true colonoscopic neoplasm miss rate is lacking. It would not be possible to remove the colons of patients included in the study and use them as the gold standard. Furthermore, it is difficult to directly visualise small or non-polypoid lesions during pathological examination. ${ }^{26}$ Computed tomographic colonography has known limited diagnostic characteristics for detection of lesions less than $6 \mathrm{~mm}$ in size $\mathrm{e}^{27-29}$ or non-polypoid shaped. ${ }^{30-32}$ In the current study, most (78\%) of the missed neoplasms were less than or equal to $5 \mathrm{~mm}$, and furthermore, a quarter $(\mathrm{n}=75)$ of the detected colorectal neoplasms were non-polypoid in morphology. ${ }^{10} 1133$ Hence, though a back-to-back colonoscopy study design may lead to incorporation bias, falsely inflating the estimates of both sensitivity and specificity, and underestimating the miss rate, ${ }^{34}$ given the similar bias and the limitations in other diagnostic modalities, it remains the most reliable method to investigate neoplasm miss rate.

Future investigators might consider the use of a different endoscopy team, who are blinded to the results of the first examination, to perform the second examination. Thus, they could minimise co-intervention and measurement biases that may be present in our trial. However, most polyp miss rate tandem colonoscopy studies have not been performed by two different, blinded examiners. ${ }^{5536}$ The one back-to-back colonoscopy study of neoplasm miss rates in which patients were randomly allocated to undergo the second colonoscopy by the same or a different endoscopist, showed no significant difference in colonoscopist performance of the second examination, despite individual technical variation. ${ }^{6}$ Another important element in the tandem colonoscopy study design is the selection of the control group. East and colleagues ${ }^{37}$ studied the neoplasm miss rate using back to back colonoscopy in patients with hereditary non-polyposis CRC and concluded that the use of NBI in the proximal colon appeared to improve adenoma detection, especially in non-polypoid lesions. We also found high rates of non-polypoid lesions using NBI, but we similarly found them using WL. The East study design, however, did not have a control arm and thus, it is difficult to determine if the appeared increased detection rate was due to the NBI effect or simply the miss rate of colonoscopy.

\section{CONCLUSIONS}

In this study, we found that NBI did not significantly affect the miss rate of neoplastic lesions compared to WL. We observed low miss rates in both arms: $0 \%$ (up to $2 \%$ ) for advanced neoplasm and $12 \%$ for all adenomas. We also found high adenoma detection rates using NBI or WL across screening and non-screening populations. Future larger, comparative studies of the diagnostic characteristics of specific colonoscope features such as wide angle of view or high definition, CT colonography and other candidate screening modalities are of interest to advance the efficacy of CRC prevention.
Acknowledgements: We thank Olympus Medical Systems Corporation, Hachioji, Japan, for the loan of the endoscopes used in this study.

Funding: TK received the Dean's Fellowships Award, Stanford University, and NIH Training grant T32 DK007056. Role of the funding source: We did not receive industry financial support for this study. The funding agencies and vendor had no role in the design and conduct of the study; collection, analysis, and interpretation of the data; in the preparation, review, or approval of the manuscript.

Competing interests: None.

Ethics approval: The institutional review board at the Veterans Affairs Palo Alto Health Care System and Stanford University School of Medicine approved the study on 8 October 2004

\section{REFERENCES}

1. Winawer SJ, Zauber AG, Ho MN, et al. Prevention of colorectal cancer by colonoscopic polypectomy. The National Polyp Study Workgroup. N Engl J Med 1993;329:1977-81

2. Muller AD, Sonnenberg A. Prevention of colorectal cancer by flexible endoscopy and polypectomy. A case-control study of 32,702 veterans. Ann Intern Med 1995;123:904-10.

3. Lieberman DA, Weiss DG, Bond JH, et al. Use of colonoscopy to screen asymptomatic adults for colorectal cancer. Veterans Affairs Cooperative Study Group 380. N Engl J Med 2000;343:162-8.

4. Imperiale TF, Wagner DR, Lin CY, et al. Risk of advanced proximal neoplasms in asymptomatic adults according to the distal colorectal findings. N Engl J Med 2000;343:169-74.

5. van Rijn JC, Reitsma JB, Stoker J, et al. Polyp miss rate determined by tandem colonoscopy: a systematic review. Am J Gastroenterol 2006;101:343-50.

6. Rex DK, Cutler CS, Lemmel GT, et al. Colonoscopic miss rates of adenomas determined by back-to-back colonoscopies. Gastroenterology 1997;112:24-8.

7. Singh H, Turner D, Xue L, et al. Risk of developing colorectal cancer following a negative colonoscopy examination: evidence for a 10 -year interval between colonoscopies. Jama 2006;295:2366-73.

8. Pickhardt PJ, Nugent PA, Mysliwiec PA, et al. Location of adenomas missed by optical colonoscopy. Ann Intern Med 2004;141:352-9.

9. Leaper M, Johnston MJ, Barclay M, et al. Reasons for failure to diagnose colorectal carcinoma at colonoscopy. Endoscopy 2004;36:499-503.

10. Soetikno R, Friedland S, Kaltenbach T, et al. Nonpolypoid (flat and depressed) colorectal neoplasms. Gastroenterology 2006;130:566-76; quiz 588-9.

11. Soetikno R, Kaltenbach T, Rouse R, et al. Prevalence of nonpolypoid (flat and depressed) colorectal neoplasms in asymptomatic and symptomatic adults. Jama 2008;299:1027-35

12. Harewood GC, Sharma VK, de Garmo P. Impact of colonoscopy preparation quality on detection of suspected colonic neoplasia. Gastrointest Endosc 2003;58:76-9.

13. Barclay RL, Vicari JJ, Doughty AS, et al. Colonoscopic withdrawal times and adenoma detection during screening colonoscopy. $N$ Engl J Med 2006;355:2533-41.

14. Chen SC, Rex DK. Endoscopy can be more powerful than age and male gender in predicting adenoma detection at colonoscopy. Am J Gastroenterol 2007;102:856-61.

15. Atkin W, Rogers $P$, Cardwell $C$, et al. Wide variation in adenoma detection rates at screening flexible sigmoidoscopy. Gastroenterology 2004;126:1247-56.

16. Gono K, Obi T, Yamaguchi M, et al. Appearance of enhanced tissue features in narrow-band endoscopic imaging. J Biomed Opt 2004;9:568-77.

17. Machida H, Sano Y, Hamamoto $Y$, et al. Narrow-band imaging in the diagnosis of colorectal mucosal lesions: a pilot study. Endoscopy 2004;36:1094-8.

18. Rex DK, Bond JH, Winawer S, et al. Quality in the technical performance of colonoscopy and the continuous quality improvement process for colonoscopy: recommendations of the U.S. Multi-Society Task Force on Colorectal Cancer Am J Gastroenterol 2002;97:1296-308.

19. Lieberman D. Colonoscopy: as good as gold? Ann Intern Med 2004;141:401-3.

20. Yasutomi M, Baba S, Hojo K, et al. Japanese classification of colorectal carcinoma Tokyo: Kanehara, 1997.

21. Hamilton S, Aaltonen L. Pathology \& genetics. Tumours of the digestive system World Health Organization classification of tumours. 2nd edn. Lyon: International Agency for Research on Cancer, 2000.

22. Aronchick CA, Lipshutz WH, Wright SH, et al. A novel tableted purgative for colonoscopic preparation: efficacy and safety comparisons with Colyte and Fleet phospho-soda. Gastrointest Endosc 2000;52:346-52.

23. Rex DK, Helbig CC. High yields of small and flat adenomas with high-definition colonoscopes using either white light or narrow band imaging. Gastroenterology 2007; 133:42-7.

24. Inoue T, Murano M, Murano N, et al. Comparative study of conventional colonoscopy and pan-colonic narrow-band imaging system in the detection of neoplastic colonic polyps: a randomized, controlled trial. J Gastroenterol 2008;43:45-50.

25. Adler A, Pohl H, Papanikolaou IS, et al. A prospective randomised study on narrowband imaging versus conventional colonoscopy for adenoma detection: does narrowband imaging induce a learning effect? Gut 2008:57:59-64.

26. Postic G, Lewin D, Bickerstaff $C$, et al. Colonoscopic miss rates determined by direct comparison of colonoscopy with colon resection specimens. Am J Gastroenterol 2002;97:3182-5. 
27. Pickhardt PJ, Choi JR, Hwang I, et al. Computed tomographic virtual colonoscopy to screen for colorectal neoplasia in asymptomatic adults. N Engl J Med 2003:349:2191-200.

28. Hwang I, Wong RK. Limitations of virtual colonoscopy. Ann Intern Med 2005;142:154-5; author reply 155

29. Cotton PB, Durkalski VL, Pineau BC, et al. Computed tomographic colonography (virtual colonoscopy): a multicenter comparison with standard colonoscopy for detection of colorectal neoplasia. Jama 2004;291:1713-9.

30. Park SH, Lee SS, Choi EK, et al. Flat colorectal neoplasms: definition, importance and visualization on CT colonography. AJR Am J Roentgenol 2007;188:953-9.

31. Fidler JL, Johnson CD, MacCarty RL, et al. Detection of flat lesions in the colon with CT colonography. Abdom Imaging 2002;27:292-300.

32. Van Gelder RE, Nio CY, Florie J, et al. Computed tomographic colonography compared with colonoscopy in patients at increased risk for colorectal cancer. Gastroenterology 2004;127:41-8.
33. Rembacken BJ, Fujii T, Cairns A, et al. Flat and depressed colonic neoplasms: a prospective study of 1000 colonoscopies in the UK. Lancet 2000;355:1211-4.

34. Whiting $\mathbf{P}$, Rutjes AW, Reitsma JB, et al. Sources of variation and bias in studies of diagnostic accuracy: a systematic review. Ann Intern Med 2004:140:189-202.

35. Rex DK, Chadalawada V, Helper DJ. Wide angle colonoscopy with a prototype instrument: impact on miss rates and efficiency as determined by back-to-back colonoscopies. Am J Gastroenterol 2003;98:2000-5.

36. Matsushita M, Hajiro K, Okazaki K, et al. Efficacy of total colonoscopy with a transparent cap in comparison with colonoscopy without the cap. Endoscopy 1998;30:444-7

37. East JE, Suzuki N, Stavrinidis M, et al. Narrow band imaging for colonoscopic surveillance in hereditary non-polyposis colorectal cancer. Gut 2008; $57: 65-70$

\section{Editor's quiz: GI snapshot}

Robin Spiller, editor

\section{Massive rectal bleeding in a patient with a history of hepatocellular carcinoma}

\section{CLINICAL PRESENTATION}

A 60-year-old woman, who is a carrier of hepatitis B and C, was diagnosed as having hepatocellular carcinoma in August 2006. She underwent laparoscopic left segmentectomy for a solitary $2 \times 2.8 \times 2.1 \mathrm{~cm}$ tumour in segment 2 of the liver. Post-operatively, her alpha-fetoprotein level decreased from a pre-operative level of $2279 \mathrm{ng} / \mathrm{ml}$ to a normal level. She was under close surveillance and there was no evidence of disease recurrence. She remained well until October 2007 when she presented with massive per rectal bleeding to our emergency department. Physical examination upon admission showed pallor and surgical scars on abdominal wall only. Blood tests revealed anaemia with a haemoglobin level of $8.5 \mathrm{~g} / \mathrm{dl}$. Other laboratory investigation results were normal. Urgent colonoscopy was performed (fig 1).

\section{QUESTION}

Based on the colonoscopy finding, what is the likely diagnosis? See page 1419 for the answer

This case is submitted by:

\section{Y Y Hwang, ${ }^{1}$ P Chan, ${ }^{1}$ I C Law, ${ }^{2}$ A T Khin, ${ }^{3}$ T Yau ${ }^{1}$}

${ }^{1}$ Department of Medicine, Queen Mary Hospital, University of Hong Kong, Hong Kong;

${ }^{2}$ Department of Medicine, Kwong Wah Hospital, Hong Kong; ${ }^{3}$ Department of

Pathology, Kwong Wah Hospital, Hong Kong

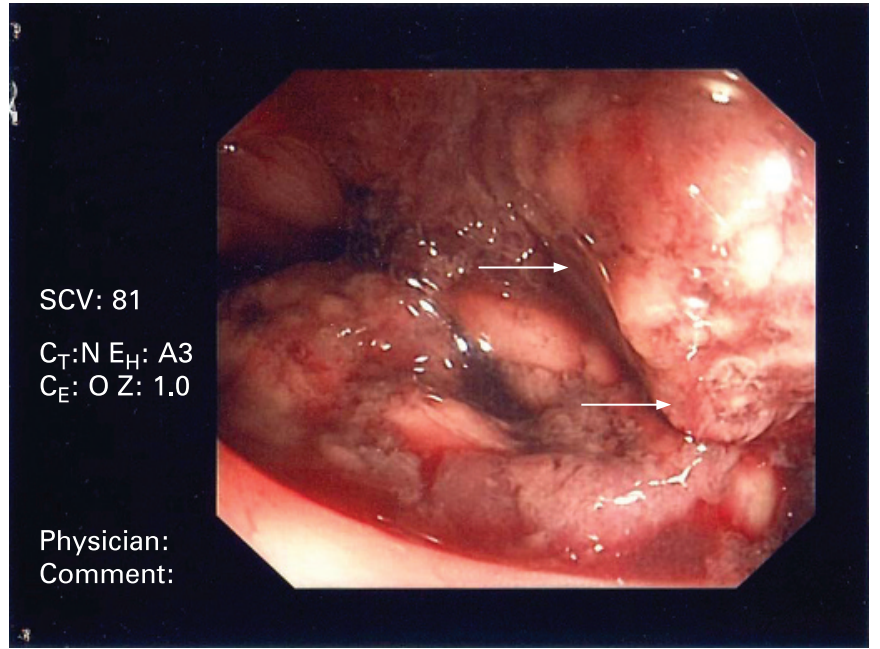

Figure 1 Endoscopic view of the colon showing a polypoid mass.

Correspondence to: Dr T Yau, University Department of Medicine, Room 405 Professorial Block, Queen Mary Hospital, 102 Pokfulam Road, Hong Kong; the@netvigator.com

Competing interests: None

Patient consent: Obtained.

Gut 2008;57:1412. doi:10.1136/gut.2008.152520 